\title{
Theoretical Study of the Reaction $\mathrm{O}\left({ }^{3} \mathrm{P}\right)+\mathrm{C}_{2} \mathrm{H}_{4}$ and Comparison with the ${ }^{3} \mathrm{CH}_{2}+\mathrm{C}_{2} \mathrm{H}_{4}$ Reaction
}

\author{
D. Wortmann-Saleh, B. Engels, and S. D. Peyerimhoff \\ Institut für physikalische und theoretische Chemie, Universität Bonn, Wegelerstrasse 12, \\ 53115 Bonn, Federal Republic of Germany
}

Received: March 30, 1994; In Final Form: July 7, $1994^{\circ}$

\begin{abstract}
The minimum energy path for the reaction $\mathrm{O}\left({ }^{3} \mathrm{P}_{\mathrm{g}}\right)+\mathrm{C}_{2} \mathrm{H}_{4}\left({ }^{1} \mathrm{~A}_{\mathrm{g}}\right)$ has been calculated by optimizing all relevant geometrical parameters along the approach of oxygen to ethene. A barrier of $4.7 \mathrm{kcal} / \mathrm{mol}$ in the ${ }^{3} \mathrm{~A}^{\prime \prime}\left(. .9 \mathrm{a}^{\prime 2}\right.$ $10 \mathrm{a}^{\prime} 3 \mathrm{a}^{\prime \prime}$ ) potential energy surface and an energy difference of $14.4 \mathrm{kcal} / \mathrm{mol}$ between the product and the fragments is found at the multireference-configuration interaction level. The corresponding values at the lower-level treatment CASSCF are $9 \mathrm{kcal} / \mathrm{mol}$ for the barrier and $9 \mathrm{kcal} / \mathrm{mol}$ for the depth of the potential; this shows the importance of inclusion of electron correlation. The barrier for $\mathrm{CH}_{2}$ rotation for the lowestenergy structure (asymmetric $\mathrm{OC}_{2} \mathrm{H}_{4}$ ) is around $5 \mathrm{kcal} / \mathrm{mol}$. The energy gap to the first excited state ${ }^{3} \mathrm{~A}^{\prime}$ $\left(. .9 a^{\prime} 10 a^{\prime} 3 a^{\prime 2}\right)$ is found to be $3.6 \mathrm{kcal} / \mathrm{mol}$ in MRD-CI calculations at the ground-state minimum. Comparison with ${ }^{3} \mathrm{CH}_{2}+\mathrm{C}_{2} \mathrm{H}_{4}$ shows that in this system the lowest-energy surface is ${ }^{3} \mathrm{~A}^{\prime}$, i.e., the state which is the excited state in $\mathrm{O}+\mathrm{C}_{2} \mathrm{H}_{4}$. This difference in energy ordering of ${ }^{3} \mathrm{~A}^{\prime}$ and ${ }^{3} \mathrm{~A}^{\prime \prime}$ states results from the fact that the $\mathrm{p}_{x}, \mathrm{p}_{y}, \mathrm{p}_{z}$ degeneracy of oxygen orbitals is lifted in ${ }^{3} \mathrm{CH}_{2}$ leading to $\mathrm{b}_{1}, \mathrm{~b}_{2}$, and $\mathrm{a}_{1} \mathrm{MOs}$ whereby the lowest $b_{2}\left(a^{\prime \prime}\right)$ remains doubly occupied; as a consequence, the reaction pattern between the oxygen and ${ }^{3} \mathrm{CH}_{2}$ approach is different, which is also quite apparent in the calculated charge transfer.
\end{abstract}

\section{Introduction}

The reaction of ethene $\mathrm{C}_{2} \mathrm{H}_{4}+\mathrm{X} \rightarrow \mathrm{C}_{2} \mathrm{H}_{4} \mathrm{X}$ with radicals $\mathrm{X}$ containing unpaired electrons have been of wide theoretical and experimental interest (see ref 1 and references therein). In particular many ab initio calculations have been undertaken in the past with $\mathrm{X}=$ halogen, ${ }^{1,2} \mathrm{CH}_{2}\left({ }^{3} \mathrm{~B}_{1},{ }^{1} \mathrm{~A}_{1}\right),{ }^{3} \mathrm{NH}_{2}\left({ }^{2} \mathrm{~A}^{\prime}\right),{ }^{4}$ and $\mathrm{O}\left({ }^{3} \mathrm{P}\right) .^{5-8}$ The reaction of $\mathrm{O}\left({ }^{3} \mathrm{P}\right)$ with ethene plays an important role not only in the combustion of ethene itself, ${ }^{9}$ but also as a prototype system for the addition of an oxygen atom across a $\mathrm{C}=\mathrm{C}$ bond, which is important in a wide variety of areas ranging from atmospheric chemistry to metabolic activation of hydrocarbon carcinogens. ${ }^{5}$

In general, reactions of $\mathrm{O}\left({ }^{3} \mathrm{P}\right)$ atoms are very similar to those with the isoelectronic ${ }^{3} \mathrm{CH}_{2}\left({ }^{3} \mathrm{~B}_{1}\right)$ radical. An exception is the reaction of these radicals with monoalkenes. For $\mathrm{O}$ atom reactions the activation energies with monoalkenes depend markedly on the reactants, and there exists a correlation between the activation energies and the ionization potentials of the alkenes. In contrast, the activation energies for the ${ }^{3} \mathrm{CH}_{2}$ reactions with various monoalkenes seem to lie in a narrow energy band. ${ }^{10}$ Because of the different behavior for the reactions of $\mathrm{O}\left({ }^{3} \mathrm{P}\right)$ and $\mathrm{CH}_{2}\left({ }^{3} \mathrm{~B}_{1}\right)$ with monoalkenes, the question arises, whether the two reaction mechanisms are the same. To clarify this question, accurate potential energy surfaces for both reactions $\mathrm{O}\left({ }^{3} \mathrm{P}\right)$ and $\mathrm{CH}_{2}\left({ }^{3} \mathrm{~B}_{1}\right)$ with alkenes will be very helpful. The reaction involving triplet methylene has already been studied by Reuter et al. ${ }^{3}$

According to Cvetanovic, ${ }^{11,12}$ the $O\left({ }^{3} \mathrm{P}\right)$ atom, when allowed to react with olefins, first adds to one of the olefinic carbons to give a triplet diradical ${ }^{\circ} \mathrm{CR}_{2} \mathrm{CR}_{2} \mathrm{O}^{\prime}$. Several studies of the reaction $\mathrm{C}_{2} \mathrm{H}_{4}+\mathrm{O}$, all using the spin unrestricted HartreeFock (UHF) formalism, have been reported previously. Bader et $\mathrm{al}^{8}{ }^{8}$ showed that the reaction path corresponds to an asymmetric approach of the reactants to form the diradical product ${ }^{\circ} \mathrm{CH}_{2} \mathrm{CH}_{2} \mathrm{O}^{\circ}$. Using a basis set of double- $\zeta$ quality

Abstract published in Advance ACS Abstracts, August 15, 1994 plus polarization functions (DZP) and partially optimized structures, they failed to find the diradical product to be stable toward dissociation, however, Yamaguchi et al. ${ }^{7}$ also used a DZP quality basis set but fully optimized the structure of the diradical. Their calculations predict that in the most stable form the unpaired spins are localized at the terminal carbon and oxygen atoms. But again, they found it unstable with respect to dissociation into $\mathrm{O}\left({ }^{3} \mathrm{P}\right)$ and $\mathrm{C}_{2} \mathrm{H}_{4}$. Dupuis et al. ${ }^{6}$ calculated the structure of the diradical in its equilibrium geometry using a DZP basis set in combination with the spin-restricted HF(RHF) method. For the structure of the transition state in addition correlation effects were included by the use of a multiconfiguration Hartree-Fock (MCHF) approach. In their work the diradical product $\mathrm{CH}_{2} \mathrm{CH}_{2} \mathrm{O}$ is found to be stable with respect to the reactants. The calculations also support that the transition state for the electrophilic addition of $\mathrm{O}\left({ }^{3} \mathrm{P}\right)$ to ethylene is asymmetric.

The present paper contains an ab initio multireference configuration interaction (MRD-CI) study of the $\mathrm{O}\left({ }^{3} \mathrm{P}\right)+\mathrm{C}_{2} \mathrm{H}_{4}$ addition. For the minimum of the potential hypersurface the rotation of the terminal $\mathrm{CH}_{2}$ group around the $\mathrm{CC}$ bond will also be considered. In addition, the energetic separation to lowlying electronic states is investigated. An interpretation will be undertaken in terms of MO diagrams. Finally the results for the $\mathrm{OC}_{2} \mathrm{H}_{4}$ system will be compared to those for ${ }^{3} \mathrm{CH}_{2} \mathrm{C}_{2} \mathrm{H}_{4}$ in order to explain the differences between the two reactions.

\section{Technical Details}

The geometrical parameters used to describe the reaction of $\mathrm{O}$ with $\mathrm{C}_{2} \mathrm{H}_{4}$ are shown in Figure 1. For the reaction $\mathrm{O}+\mathrm{C}_{2} \mathrm{H}_{4}$ the distance between the attacked carbon and the oxygen, $R_{\mathrm{co}}$, can be looked upon as leading parameter of the reaction coordinate. Therefore for fixed $R_{\mathrm{Co}}$ all other parameters, $(\theta$, $R_{\mathrm{CC}}, \alpha_{1}, \alpha_{2}, \beta_{1}, \beta_{2}, R_{\mathrm{CH}}$ ) were optimized on UMP2 (MoellerPlesset second-order correction based on unrestricted HartreeFock) level using the gradient optimization algorithms of the GAUSSIAN program package. ${ }^{13}$ For a better description of 


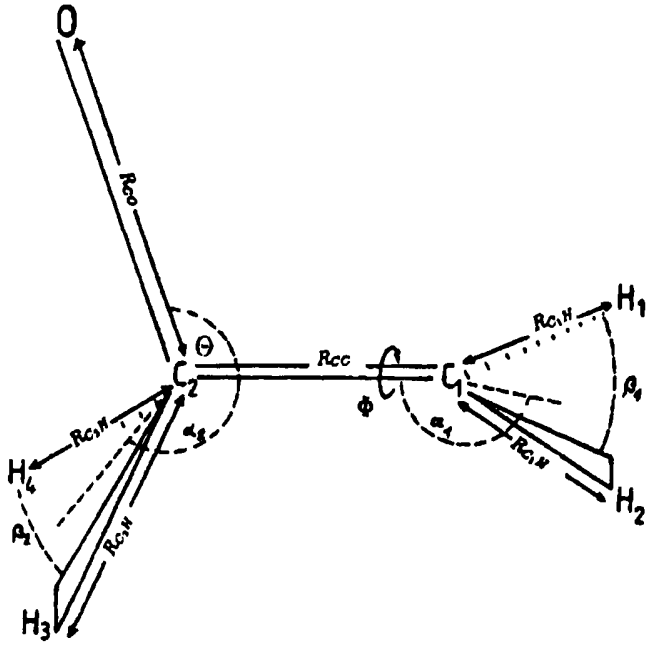

Figure 1. Definition of parameters and coordinate system employed in the present work.

possible reaction barriers the reaction path (or more exactly the minimum energy pathway) was calculated using the multireference configuration interaction approach. Along this path the angle $\Phi$, which describes the rotation of the $\mathrm{CH}_{2}$ group around the $\mathrm{CC}$ bond, was kept zero; the rotation of the $\mathrm{CH}_{2}$ group was only studied at the absolute minimum of the entire potential surface. The basis set employed in the calculations was a standard Huzinaga $(9 s 5 p)^{14}$ set of Gaussian type orbitals for the heavy atoms in a Dunning [4a2p] contraction. ${ }^{15}$ Two additional $d$ functions with exponents 1.4 and 0.35 for carbon and 1.7 and 0.425 for oxygen were introduced; a p function with exponent 0.059 was furthermore added at the oxygen. For hydrogen the (5s) basis by Whitten et al. ${ }^{16}$ was used in a [2s] contraction with a scaling factor $\eta^{2}=2.0$. Polarization $\mathrm{p}$ functions with exponents 0.735 were added to the hydrogen.

For the multireference configuration interaction (MRD-CI) treatment complete active space SCF (CASSCF) molecular orbitals were taken as the one particle basis. In the CASSCF calculations eight active electrons (the four $p$ electrons on oxygen and the $\pi$ and $\sigma$ (CC) electrons on ethene) were distributed among eight active orbitals. For the calculation of the reaction path the multireference MRD-CI was used. ${ }^{17}$ The calculations were performed with six reference configurations. The total MRD-CI configuration spaces which arise from single and double excitations with respect to the reference configurations were in the order of $30 \times 10^{6}$. The MRD-CI and estimated full $\mathrm{CI}$ (multireference-analogue of the Davidson correction) energies were evaluated in the standard manner ${ }^{17}$ whereby the secular equations actually solved were in the order of 20000 corresponding to a configuration selection threshold of 3.5 $\mu$ hartrees. The lowest occupied molecular orbitals (MOs) corresponding to the $1 \mathrm{~s}$ orbitals of carbon and oxygen were always kept doubly occupied. In addition the same number of the highest virtual orbitals were discarded in the MRD-CI.

\section{Results and Discussion}

The calculated minimum energy path for the reaction $O\left({ }^{3} \mathrm{P}_{\mathrm{g}}\right)$ $+\mathrm{C}_{2} \mathrm{H}_{4}\left({ }^{1} \mathrm{~A}_{\mathrm{lg}}\right)$ is shown in Figure 2. The optimized geometrical parameters as a function of $R_{\mathrm{CO}}$ are listed in Table 1 . The optimal structure is found for the following geometry: $R_{\mathrm{CO}}=$ $1.40 \AA, \theta=114^{\circ}, R_{\mathrm{CC}}=1.49 \AA, \alpha_{2}=128^{\circ}, \alpha_{1}=194^{\circ}, \beta_{2}=$ $106^{\circ}, \beta_{1}=118^{\circ}, R_{\mathrm{C}_{2} \mathrm{H}}=1.10 \AA$, and $R_{\mathrm{C}_{\mathrm{H}} \mathrm{H}}=1.08 \AA$. The angle $\Phi$ which describes the rotation around the CC bond is thereby kept fixed at $\Phi=0^{\circ}$, its influence will be discussed

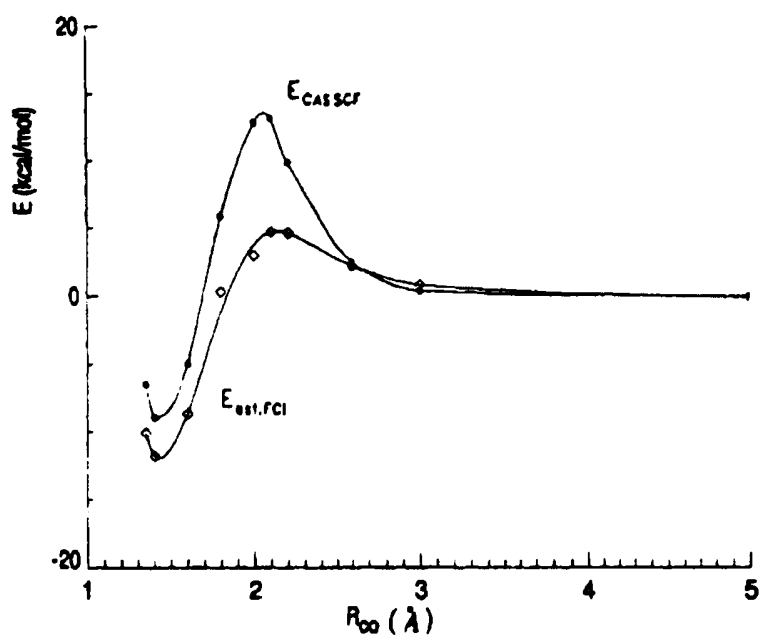

Figure 2. Calculated minimum energy path for the $\mathrm{O}-\mathrm{C}_{2} \mathrm{H}_{4}$ approach as obtained from the CASSCF and MRD-CI calculations.

separately. The optimized structure is in good agreement with the geometries determined by Yamaguchi et al. ${ }^{7}$ The ${ }^{3} \mathrm{~A}^{\prime \prime}(\sigma, \pi)$ was found to be the ground state. In analogy to the work of Yamaguchi the labels $(\sigma, \pi)$ describe the orientation of the unpaired electrons on the terminal carbon and on the oxygen: the first character in the parenthesis refers always to the unpaired electron on carbon, the second character to the unpaired electron located at the oxygen: furthermore $\sigma$ means the unpaired electron orbital is in the CCO symmetry plane while $\pi$ indicates that it is out-of-plane. The ${ }^{3} \mathrm{~A}^{\prime \prime}(\sigma, \pi)$ has the electronic configuration $1 \mathrm{a}^{\prime 2} \ldots 9 \mathrm{a}^{\prime 2} 10 \mathrm{a}^{\prime} 1 \mathrm{a}^{\prime 2} 2 \mathrm{a}^{\prime \prime 2} 3 \alpha^{\prime \prime}$. The total CASSCF energy for the ground state minimum is -152.9308 hartrees; the MRD-CI energy is -153.2905 hartrees while the corresponding value for the estimated full $\mathrm{CI}$ is -153.3250 hartrees.

In considering the addition of oxygen to ethene the decrease in the $\mathrm{CO}$ separation leading to the optimal $\mathrm{OC}_{2} \mathrm{H}_{4}$ structure influences the other geometrical parameters describing the change from $\mathrm{sp}^{2}$ to $\mathrm{sp}^{3}$ hybridization of the attacked carbon center (Figure 1). The angle $\alpha_{2}$ changes from $180^{\circ}$ in the separated systems to $128^{\circ}$ in the $\mathrm{OC}_{2} \mathrm{H}_{4}$ minimum. Furthermore a distinct elongation of the $\mathrm{CC}$ bond from the double bond value to almost that of a single bond is found and finally the angle $\beta_{2}$ decreases from $118^{\circ}$ to $106^{\circ}$.

On all levels of our calculations the $\mathrm{OC}_{2} \mathrm{H}_{4}$ biradical is found to be stable relative to dissociation into the $\mathrm{O}\left({ }^{3} \mathrm{P}\right)+\mathrm{C}_{2} \mathrm{H}_{4}$ fragments. The energy difference between fragments and product is $14.4 \mathrm{kcal} / \mathrm{mol}$ on estimated full $\mathrm{CI}$ level; it is 9.0 $\mathrm{kcal} / \mathrm{mol}$ on CASSCF and $12.6 \mathrm{kcal} / \mathrm{mol}$ on the MRD-CI level of treatment. The results show furthermore a definite barrier between fragments and product (1). The CASSCF calculations predict a transition state of $8.9 \mathrm{kcal} / \mathrm{mol}$ above the reactants while the estimated full $\mathrm{CI}$ gives an activation energy of only $4.7 \mathrm{kcal} / \mathrm{mol}$. The top of the barrier is found at $R_{\mathrm{CO}}=2.1 \AA$. In the earlier work of Dupuis et al. ${ }^{6}$ the multiconfiguration selfconsistent field (MCSCF) calculations predicted a transition state $16 \mathrm{kcal} / \mathrm{mol}$ above the reactants. From these results it is obvious that proper inclusion of electron correlation is very important for the description of the barrier height. The present value of $4.7 \mathrm{kcal} / \mathrm{mol}$ is still about $2 \mathrm{kcal} / \mathrm{mol}$ above the experimental value of $2 \mathrm{kcal} / \mathrm{mol} .^{18}$ It is conceivable that this difference can be reduced if geometry optimization is carried out at the MRDCI level (instead of UMP2) and if further extension in the AO basis and the $\mathrm{CI}$ treatment is made. At the same time one should keep in mind that the experimental value cannot be directly compared to the barrier height in the potential energy hyper- 


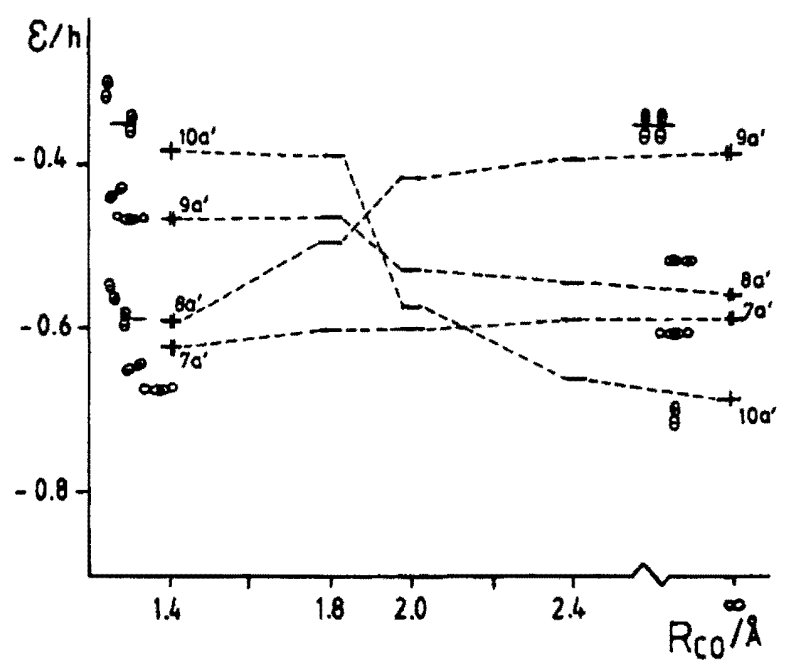

Figure 3. Orbital energy diagram for the $a^{\prime}$ orbitals in the $\mathrm{O}-\mathrm{C}_{2} \mathrm{H}_{4}$ approach.

surface. This can already be seen by including vibrational effects which reduce the calculated value of the barrier by 0.5 $\mathrm{kcal} / \mathrm{mol}$.

The molecular orbitals of the $\mathrm{O}-\mathrm{C}_{2} \mathrm{H}_{4}$ system can be distinguished on the basis of symmetry considerations in those, lying perpendicular to the CCO plane ( $a^{\prime \prime}$ symmetry) and orbitals, lying within the $\mathrm{CCO}$ plane ( $\mathrm{a}^{\prime}$ symmetry). It is found that the orbitals of $a^{\prime \prime}$ symmetry $\left(1 b_{2 u}\right.$ and $1 b_{1 g}$ of ethene and one singly occupied $p$ function on oxygen) are not directly involved in bond formation; i.e., very little mixing between these orbitals is found along the minimum energy path. The MOs affected most in the reaction are the in-plane $p$ functions on $O$ and the ethylene $3 \sigma_{g}$-type $\left(3 \mathrm{a}_{\mathrm{g}}\right)$ and $\pi$ (in-plane $\pi$ ) MOs. The MO correlation diagram of these orbitals is given in Figure 3 . Note that the orbital energy of the open-shell orbital $\left(10 a^{\prime}\right)$ is obtained in a different field in the SCF procedure so that its energy cannot be directly compared with those of the doubly occupied species. At large separation of oxygen and $\mathrm{C}_{2} \mathrm{H}_{4}$ the $7 a^{\prime}$ represents the $\sigma(C C)$ bond in ethene while the $9 a^{\prime}$ is the $\pi$ orbital. The oxygen lone pair is the doubly occupied 8a'; the $10 a^{\prime}$ is one of the singly occupied oxygen $p$ functions while the other singly occupied p possesses $\mathrm{a}^{\prime \prime}$ character. In the reaction process the doubly occupied oxygen $p$ function is aligned perpendicular to the $\mathrm{CO}$ bond while the other $\mathrm{p}$ function points along the $\mathrm{CO}$ bond.

During bond formation the $\sigma(\mathrm{CC}) \mathrm{MO}$ mixes with the (doubly occupied) $p$ on oxygen. The bonding linear combination (7a') represents an in-plane $\pi$-type $\mathrm{CO}$ bond (Figure 3) while in the corresponding negative linear combination $\left(9 a^{3}\right)$ the oxygen lone-pair character is dominant. The $\pi$ and $\pi^{*}$ orbitals of ethene mix formally in the $\mathrm{O}+\mathrm{C}_{2} \mathrm{H}_{4}$ approach and lead to two carbon $p$ functions localized on the inner and terminal carbon centers respectively. The carbon $\mathrm{p}$ function on the attacked carbon interacts with the (singly occupied) $p$ function on oxygen resulting in a $\sigma$-type $\mathrm{CO}$ bond $\left(\mathbf{8 a}^{\prime}\right)$. The terminal carbon $\mathrm{p}$ function mixes only slightly with the oxygen function so that in the product $\mathrm{OC}_{2} \mathrm{H}_{4}$ the singly occupied $10 \mathrm{a}^{\prime}$ is essentially a p function located at the terminal carbon. The remaining antibonding linear combination of $\pi, \pi^{*}$ and oxygen $p$ is considerably higher in energy.

Using Koopmann's theorem, ${ }^{19}$ the 1 s orbital energies can be compared with the measured peaks of X-ray photoelectron spectroscopy (XPS). ${ }^{20}$ It can be shown that the higher the innershell orbital energy, the more negative are the surroundings of

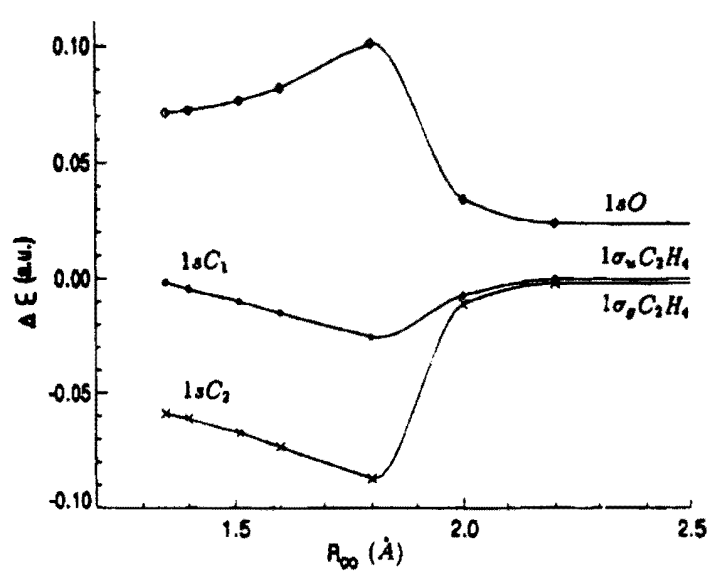

Figure 4. Orbital energy curves of the three inner shells for the $\mathrm{O}-\mathrm{C}_{2} \mathrm{H}_{4}$ approach.

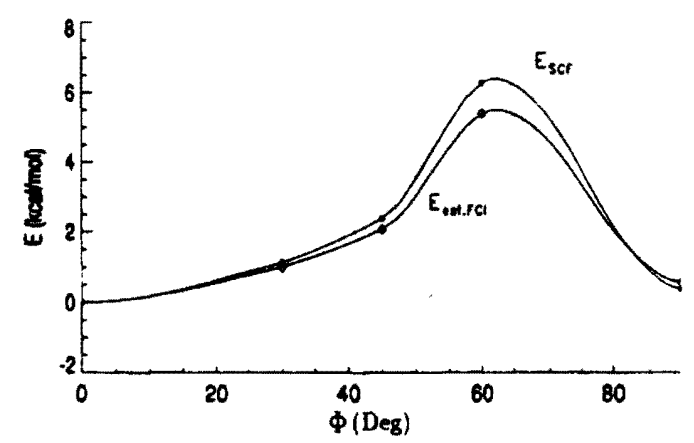

Figure 5. Calculated total energy for the optimal $\mathrm{OC}_{2} \mathrm{H}_{4}$ structure as a function of the rotational angle $\Phi$.

the atom under consideration. ${ }^{21}$ As can be seen from the $1 \mathrm{~s}$ orbital energies on oxygen and the $1 \sigma_{\mathrm{g}}$ and $1 \sigma_{\mathrm{u}}$ on ethene (Figure 4) a charge transfer from ethene to the attacking oxygen takes place during the reaction. From the orbital energies the reaction can be separated into two phases: the electrophilic phase with the transfer of charge density to the attacking oxygen with the maximum charge transfer at $R_{\mathrm{CO}}=1.8 \AA$ is followed by a nucleophilic phase with a minor charge transfer back to the ethene fragment. The top of the barrier in the SCF potential surface thus coincides with the change from the electrophilic to the nucleophilic phase. As expected, considerably more charge depletion is seen at the attacked carbon than at the terminal carbon. The change in the inner-shell orbital energies thus indicates a partial ionic structure $\mathrm{O}^{-} \mathrm{C}_{2} \mathrm{H}_{4}{ }^{+}$at the absolute minimum while the lowest dissociation limit refers to neutral species. Hence the reaction barrier can be viewed as a result of the interaction between the ionic and the covalent states. Because of the low symmetry such mixing (avoided crossing) already occurs at the MO level rather than at the configuration level.

The calculated energy for $\mathrm{CH}_{2}$ rotation around the $\mathrm{CC}$ bond is given in Figure 5. The variation in the parameter $\Phi$ was undertaken for the equilibrium structure, keeping all other geometrical parameters fixed. The potential curve was calculated at the single-double CI (SD-CI) level because multireference effects are not expected to be important for this distortion, using the COLUMBUS program package. 22 The present calculations predict the lowest energy at $\Phi=0^{\circ}$ the energy maximum is found for an angle around $60^{\circ}$. The predicted barrier height is around $5-6 \mathrm{kcal} / \mathrm{mol}$. Such a small rotational barrier is only possible for CC single bonds; the barrier to 
TABLE 1: Optimized Geometrical Parameters for the Reaction $O\left({ }^{3} P_{\varepsilon}\right)+C_{2} H_{4}\left({ }^{1} A_{1 g}\right)$ as a Function of $R_{c o}$ (for Notation See Figure 1) As Obtained from UMP2 Calculations

\begin{tabular}{|c|c|c|c|c|c|c|c|c|}
\hline$R_{\mathrm{Co}}[\AA]$ & $\theta$ [deg] & $R_{\mathrm{Cc}}[\AA]$ & $\alpha_{2}$ [deg] & $\alpha_{1}$ [deg] & $\mathrm{C}_{1} \mathrm{H}[\mathrm{A}]$ & $\mathrm{C}_{2} \mathrm{H}[\boldsymbol{A}]$ & $\beta_{1}[\mathrm{deg}]$ & $\beta_{2}$ [deg] \\
\hline 1.15 & 115 & 1.53 & 120 & 201 & 1.08 & 1.14 & 117 & 94 \\
\hline 1.25 & 115 & 1.51 & 123 & 196 & 1.08 & 1.12 & 117 & 101 \\
\hline 1.35 & 115 & 1.49 & 126 & 194 & 1.08 & 1.10 & 117 & 104 \\
\hline 1.404 & 114 & 1.49 & 128 & 194 & 1.08 & 1.10 & 118 & 106 \\
\hline 1.45 & 113 & 1.48 & 130 & 194 & 1.08 & 1.10 & 118 & 107 \\
\hline 1.51 & 112 & 1.47 & 133 & 194 & 1.08 & 1.09 & 118 & 108 \\
\hline 1.60 & 110 & 1.46 & 134 & 193 & 1.08 & 1.09 & 118 & 110 \\
\hline 1.80 & 105 & 1.41 & 150 & 190 & 1.08 & 1.09 & 118 & 114 \\
\hline 2.00 & 99 & 1.34 & 166 & 184 & 1.08 & 1.08 & 118 & 117 \\
\hline 2.10 & 99 & 1.32 & 167 & 184 & 1.08 & 1.08 & 118 & 117 \\
\hline 2.20 & 98 & 1.31 & 174 & 181 & 1.08 & 1.08 & 118 & 118 \\
\hline
\end{tabular}

TABLE 2: Relative Energies (kcal/mol) of Low-Lying ${ }^{3} \mathrm{OCH}_{2} \mathrm{CH}_{2}$ Diradical Electronic States

\begin{tabular}{lcc}
\hline \multicolumn{1}{c}{ states } & $E_{\text {SCF }}$ & $E_{\text {est. }}$ \\
\hline $\mathrm{X}^{3} \mathrm{~A}^{\prime \prime}(\sigma, \pi), \ldots 8 \alpha^{\prime 2} 9 \mathrm{a}^{\prime 2} 10 \mathrm{a}^{\prime} 3 \mathrm{a}^{\prime \prime}$ & 0.0 & 0.0 \\
$(\pi, \pi), 90^{\circ}$ rotation & 0.5 & 3.9 \\
$\mathrm{~A}^{3} \mathrm{~A}^{\prime}(\sigma, \sigma), \ldots 8 \mathrm{a}^{2} 9 \mathrm{a}^{\prime} 10 \mathrm{a}^{\prime} 3 \mathrm{a}^{\prime 2}$ & 2.1 & 3.6 \\
$(\pi, \sigma), 90^{\circ}$ rotation & 1.2 & 4.8
\end{tabular}

rotation around the double bond in the ethene fragment is 65 $\mathrm{kcal} / \mathrm{mol}$. It is seen from Table 1 that the change from the double-bond to the single-bond character occurs in the region of the $\mathrm{O}+\mathrm{C}_{2} \mathrm{H}_{4}$ reaction barrier $\left(R_{\mathrm{CO}}=1.8 \AA\right)$. For example, the $\mathrm{CC}$ bond changes from $1.34 \AA$ at $R_{\mathrm{CO}}=2.0 \AA$ to $1.46 \AA$ at $R_{\mathrm{CO}}=1.6 \AA$. A similar trend indicating the rapid change from $\mathrm{sp}^{2}$ to $\mathrm{sp}^{3}$ hybridization during the reaction is seen in the value of the angle $\alpha\left(166^{\circ}\right.$ at $R_{\mathrm{CO}}=2.0 \AA$ and $134^{\circ}$ at $\left.R_{\mathrm{CO}}=1.6 \AA\right)$. On the basis of these facts it can be assumed that the rotation around the CC bond is not an important factor in determining the minimum energy path for the $\mathrm{O}+\mathrm{C}_{2} \mathrm{H}_{4}$ approach. The two extreme points, i.e., $0^{\circ}$ rotation and $90^{\circ}$ rotation have also been computed employing the MRD-CI treatment using $C_{s}$ symmetry. The results are given in Table 2 and show that $\Phi$ $=0^{\circ}$ is indeed the preferred structure. Our SCF values are similar to those obtained earlier. ${ }^{6.7}$ To compare the reaction $\mathrm{O}$ $+\mathrm{C}_{2} \mathrm{H}_{4}$ with that of $\mathrm{CH}_{2}+\mathrm{C}_{2} \mathrm{H}_{4}$, it is necessary to consider also the first electronically excited state $9 a^{\prime} \rightarrow 3 a^{\prime \prime}$. This state corresponds to the electronic ground state of the ${ }^{3} \mathrm{CH}_{2}+\mathrm{C}_{2} \mathrm{H}_{4}$ surface. The excitation energy at the ground state minimum is only $3.6 \mathrm{kcal} / \mathrm{mol}$ at the estimated full $\mathrm{CI}$ level (Table 2). This very small difference can easily be understood from the fact that the excitation takes place between two, primarily at the oxygen-localized p orbitals. In the dissociation limit both states are degenerate.

\section{Comparison between ${ }^{3} \mathrm{OC}_{2} \mathrm{H}_{4}$ and ${ }^{3} \mathrm{CH}_{2} \mathrm{C}_{2} \mathrm{H}_{4}$}

One major difference between the two isoelectronic systems is the fact that the ground-state $\mathrm{OC}_{2} \mathrm{H}_{4}$ is a ${ }^{3} \mathrm{~A}^{\prime \prime}$ state while in ${ }^{3} \mathrm{CH}_{2} \mathrm{C}_{2} \mathrm{H}_{4}$ both singly occupied orbitals lie within the same symmetry plane to give a ${ }^{3} \mathrm{~A}^{\prime}$ state (3). The reason for this difference can be traced to the symmetry of the attacking agents. In the oxygen atom with spherical symmetry the three p orbitals are degenerate; assuming the $\mathrm{CCO}$ plane to be the $y z$ plane, the $p_{z}$ and $p_{y}$ orbitals belong to $A^{\prime}$ and the $p_{x}$ orbital to $A^{\prime \prime}$ symmetry. During the reaction the degeneracy is lifted and the state corresponding to an oxygen $\mathrm{p}_{x}^{1}\left(\mathrm{p}_{y} \mathrm{p}_{z}\right)^{3}$ occupation in the fragmentation channel becomes the ground state of the combined system.

In the ${ }^{3} \mathrm{CH}_{2}+\mathrm{C}_{2} \mathrm{H}_{4}$ reaction the degeneracy is already lifted in the fragmentation channel due to the interaction of the carbon $\mathrm{p}$ function with the two hydrogen atoms. In $C_{2 v}$ symmetry the corresponding orbitals are $1 b_{2}, 3 a_{1}$, and $1 b_{1}$. The $b_{2}$ is a linear combination of $\mathrm{p}_{x}$ and $\left(1 \mathrm{~s}\left(\mathrm{H}_{1}\right)-1 \mathrm{~s}\left(\mathrm{H}_{2}\right)\right)$, possessing $\mathrm{A}^{\prime \prime}$ sym-
TABLE 3: Extreme Points on the Hypersurface for the Systems $\mathrm{OC}_{2} \mathrm{H}_{4}$ and $\mathrm{CH}_{2} \mathrm{C}_{2} \mathrm{H}_{4}$, Taken Relative to the Dissociation Limit (Estimated Full CI Energies); $X=0$, $\mathbf{C H}_{2}$

\begin{tabular}{llc}
\hline & $\mathrm{OC}_{2} \mathrm{H}_{4}$ & $\mathrm{CH}_{2} \mathrm{C}_{2} \mathrm{H}_{4}{ }^{3}$ \\
\hline$R_{\mathrm{cx}}, \AA$ & 1.40 & 1.51 \\
$\theta$, deg & 114 & 106 \\
$R_{\mathrm{cc}}, \AA$ & 1.48 & 1.51 \\
$\alpha_{2}$ deg & 128.5 & 122.4 \\
$\alpha_{1}$, deg & 194.5 & 170.0 \\
$\beta_{2}$, deg & 106.0 & 106.0 \\
$\beta_{1}$, deg & 117.0 & 118.0 \\
$\beta_{3}$, deg & & 107.0 \\
$\alpha_{3}$, deg & & 170.0 \\
barrier to direct dissociation, & $4.7^{a}$ & $7.5^{b}$ \\
kcal/mol (neglecting \\
vibrational effects) \\
absolute minimum energy, kcal/mol & & \\
$\quad$ & 14.4 & 33.0
\end{tabular}

${ }^{a}$ Experimental activation energy $=2.0 \mathrm{kcal} / \mathrm{mol} .^{18} \mathrm{~b}$ Experimental activation energy $=5.3 \mathrm{kcal} / \mathrm{mol} .^{10}$

metry in the combined system. In $\mathrm{CH}_{2}$ it is the lowest of the three orbitals because of its strong $\mathrm{CH}$ bonding character. The singly occupied $3 a_{1}$ and $1 b_{1}$ lie within the symmetry plane of the combined $\mathrm{CH}_{2} \mathrm{C}_{2} \mathrm{H}_{4}$ system. While the $1 b_{1}$ is a pure $p$ function on carbon, perpendicular to the line of $\mathrm{CH}_{2}-\mathrm{C}_{2} \mathrm{H}_{4}$ approach, the $3 a_{1}$ is the in-plane $p$ function with some hydrogen admixture; it points along the newly formed $\mathrm{CC}$ bond.

From this description it is clear that the $\mathrm{OC}_{2} \mathrm{H}_{4}$ ground-state occupation, i.e., $9 a^{\prime 2} 10 a^{\prime} 3 a^{\prime \prime}$, is not energetically favored in $\mathrm{CH}_{2} \mathrm{C}_{2} \mathrm{H}_{4}$ because this would request single occupation of the low-lying $1 b_{2}$-type orbital of $\mathrm{CH}_{2}$ with its strong $\mathrm{CH}$ bonding character. Therefore, the $9 a^{\prime} 10 a^{\prime} 3 a^{\prime \prime 2}$ occupation is the ground state for $\mathrm{CH}_{2} \mathrm{C}_{2} \mathrm{H}_{4}$. This occupation corresponds to the first electronically excited $\mathrm{OC}_{2} \mathrm{H}_{4}$ state. The fact, that the geometry of $\mathrm{CH}_{2} \mathrm{C}_{2} \mathrm{H}_{4}$ and $\mathrm{OC}_{2} \mathrm{H}_{4}$ are quite similar as seen from Table 3 is nevertheless not very surprising. The geometry-determining factor in both reactions is the change in the hybridization of the attacked carbon from $\mathrm{sp}^{2}$ to $\mathrm{sp}^{3}$ which is accompanied by the change from a double to a single $\mathrm{CC}$ bond.

In comparing the minimal energy path of the two systems one observes a much larger charge transfer in the oxygen reaction. The shift in the 1s orbital energy of the attacked carbon is about $2.7 \mathrm{eV}$ in the $\mathrm{O}+\mathrm{C}_{2} \mathrm{H}_{4}$ reaction while it is only $0.7 \mathrm{eV}$ in the $\mathrm{CH}_{2} \mathrm{C}_{2} \mathrm{H}_{4}$ formation. It is therefore conceivable that the ionization energy of the alkene reacting with oxygen influences the ease of the charge transfer and with this the height of the activation barrier. Because most of the charge transfer seems to occur in the ethene $\pi$-system, smaller effects are expected for alkane systems.

\section{Summary}

In the present work the reaction of ${ }^{3} \mathrm{O}$ with $\mathrm{C}_{2} \mathrm{H}_{4}$ has been studied, and the results have been compared to those for the 
${ }^{3} \mathrm{CH}_{2} \mathrm{C}_{2} \mathrm{H}_{4}$ system. The minimum-energy path (MEP) was calculated and the optimization of all geometrical parameters has been performed on UMP2 level. The ${ }^{3} \mathrm{~A}^{\prime \prime}(\sigma, \pi)$ with the electronic configuration $1 a^{\prime 2} \ldots 9 a^{\prime 2} 10 a^{\prime} 1 a^{\prime \prime 2} 2 a^{\prime \prime 2} 3 a^{\prime \prime}$ was found to be the ground state. The energy difference between the fragments and product is calculated to be $14.4 \mathrm{kcal} / \mathrm{mol}$ and the barrier towards ${ }^{3} \mathrm{O}+\mathrm{C}_{2} \mathrm{H}_{4}$ dissociation is found to be 4.2 $\mathrm{kcal} / \mathrm{mol}$. An analysis based on MO correlation diagrams explained the qualitative feature of the MEP.

For the analogous approach of ${ }^{2} \mathrm{~F}+\mathrm{C}_{2} \mathrm{H}_{4}$ the $\mathrm{MO}$ analysis with respect to composition along the reaction coordinate is qualitatively the same. $^{1}$

The change in the inner-shell orbital energies indicates a partial ionic structure $\mathrm{O}^{-} \mathrm{C}_{2} \mathrm{H}_{4}{ }^{+}$at the absolute minimum. This ionic behavior is even more present in the corresponding fluorine compound, as expected. ${ }^{l}$

If rotation around the $\mathrm{CC}$ axis is considered by varying the angle $\Phi$, whereby all other geometrical parameters are held fixed at their values corresponding to the optimal structure, it is found that the structure with $\Phi=0^{\circ}$ is the preferred one. The predicted barrier height towards rotation was between 5 and 6 $\mathrm{kcal} / \mathrm{mol}$ with a maximum at about $\Phi=60^{\circ}$. The first electronically excited state ${ }^{3} \mathrm{~A}^{\prime}(\sigma, \sigma)$ was also computed, the excitation energy is $3.6 \mathrm{kcal} / \mathrm{mol}$ at the ground-state minimum. In the ${ }^{3} \mathrm{~A}^{\prime}$ state the oxygen has the same orbital occupation as triplet methylene during the addition to ethene and the $\mathrm{MO}$ diagram is identical to that found for the reaction of ${ }^{3} \mathrm{CH}_{2}$ with $\mathrm{C}_{2} \mathrm{H}_{4}$, if we take into account, that because of the symmetry lowering, the orbitals $9 a^{\prime}$ and $10 a^{\prime}$ are split and located at the atoms $\mathrm{O}$ and $\mathrm{C}$ (terminal).

As we have seen, the two isoelectronic systems $\mathrm{OC}_{2} \mathrm{H}_{4}$ and $\mathrm{CH}_{2} \mathrm{C}_{2} \mathrm{H}_{4}$ have different electronic states in their absolute minima. From this it is clear that the active spaces and orbitals mixing for the reactions of ${ }^{3} \mathrm{O}$ or ${ }^{3} \mathrm{CH}_{2}$ with ethene are different. For the ${ }^{3} \mathrm{OC}_{2} \mathrm{H}_{4}$ system the interaction of MOs results in a definite charge transfer from ethene to the attacking oxygen, while for ${ }^{3} \mathrm{CH}_{2} \mathrm{C}_{2} \mathrm{H}_{4}$ the carbon atoms possess almost equivalent charges at the minimum geometry. ${ }^{3}$

Acknowledgment. The authors want to thank Prof. H. G. Wagner for initiating the study and providing helpful suggestions during the course of the work. The financial support of the Deutsche Forschungsgemeinschaft is gratefully acknowledged (Leibniz Prize). The computer time provided by the Computer Center of the university of Bonn and by the CONVEX of the SFB 334 have been essential to this study.

\section{References and Notes}

(1) Engels, B.; Peyerimhoff, S. D. J. Phys. Chem. 1989, 93, 4462.

(2) Engels, B.; Peyerimhoff, S. D. J. Phys. Chem. 1990, 94, 1267.

(3) Reuter, W.; Engels, B.; Peyerimhoff, S. D. J. Phys. Chem. 1992, 96,6221 .

(4) Shih, S.; Buenker, R. J.; Peyerimhoff, S. D.; Michejda, C. J. J. Am. Chem. Soc. 1972, 94, 7620.

(5) Roszak, S.; Buenker, R. J.; Hariharan, P. C.; Kaufman, J. J. Chem. Phys. 1990, 147, 13.

(6) Dupuis, M.; Wendoloski, J. J.; Takada, T.; Lester, W. A. J. Chem. Phys. 1982, 76, 481.

(7) Yamaguchi, K.; Yabustita, S.; Fueno, T.; Kato, S.; Morokuma, K. Chem. Phys. Lett. 1980, 70, 27.

(8) Bader, R. F. W.; Stephens, M. E.; Gangi, R. A. Can. J. Chem. $1977,55,2755$.

(9) Schmoltner, A. M.; Chu, P. M.; Brudzynski, R. J.; Lee, Y. T. J. Chem. Phys. 1989, 91, 6926.

(10) Kraus, H.; Oehlers, C.; Temps, F.; Wagner, H. Gg.; Wolf, M. Ber. Bunsen-Ges. Phys. Chem. 1993, 97, 545.

(11) Cvetanovic, R. J. Adv. Photochem. 1963, I, 155.

(12) Cvetanovic, R. J. Phys, Chem. 1970, 74, 2730.

(13) Frisch, M. J.; Binkley, J. S.; Schlegel, H. B.; Raghavachari, K.; Melius, C. F.; Martin, R. L.; Stewart, J. J. P.; Bobrovicz, F. W.; Rohlfing, C. M.; Kahn, L. R.; Defrees, D. J.; Seeger, R.; Whiteside, R. A.; Fox, D. F.; Fleuder, E. M.; Pople, J. A. Gaussian86. Mellon Quantum Chemistry Publishing Unit, Pittsburgh, PA, 1984.

(14) Huzinaga, S. J. Chem. Phys. 1965, 42, 1293.

(15) Dunning, T. H. J. Chem. Phys. 1970, 53, 2823.

(16) Whitten, J. L., given in the Appendix of: Peyerimhoff, S. D.; Buenker, R. J.; Allen, L. C. J. Chem. Phys. 1966, 45, 734.

(17) Buenker, R. J.; Peyerimhoff, S. D. In New Horizons in Quantum Chemsitry; Löwdin, P. O., Pullmann, B., Eds.; Reidel: Dordrecht, 1983.

(18) Westleyn, F.; Herron, J. T.; Cvetanovic, R. J.; Hampson, R. F.; Mallard, W. G. NIST Standard Reference Database 17, Version 3.0; Nationa

(19) Koopmans, T. A. Physica 1933, 1, 104.

(20) Heator, M. M.; El-Talbi, M. R. J. Chem. Phys. 1986, 85, 7198.

(21) Buenker, R. J.; Peyerimhoff, S. D. Chem. Phys. Lett. 1969, 3, 37.

(22) Shepard, R.; Shavitt, 1.; Pitzer, R. M.; Comeau, D. C.; Pepper, M.; Lischka, H.; Szalay, P. G.; Ahlrichs, R.; Brown, F. B.; Zhao, J.-G. Int. J. Quantum Chem. 1988, S22, 149-165. 